\title{
LETRAMENTO CARTOGRÁFICO DO PEDAGOGO: UMA ANÁLISE CURRICULAR DE UM CURSO SUPERIOR DE PEDAGOGIA
}

PEDAGOGIC CARTOGRAPHIC LITERACY: A CURRICULAR ANALYSIS OF A HIGHER PEDAGOGY COURSE

\section{LITERACIDAD CARTOGRÁFICA PEDAGOGIA: UN ANÁLISIS CURRICULAR DE UN CURSO DE PEDAGOGÍA MAYOR}

\author{
Daniel Cardoso Alves ${ }^{1}$ \\ dca.uemg@gmail.com \\ Isabel Cristina Alves da Silva Frade ${ }^{2}$ \\ dca.uemg@gmail.com
}

\section{RESUMO}

Este artigo tem como objetivo investigar o que propõe o currículo do curso de Pedagogia de uma universidade estadual em relação ao letramento cartográfico do pedagogo. Adota-se uma abordagem qualitativa e utiliza-se dos procedimentos pesquisa bibliográfica e documental. Ao todo, foi possível analisar 89 componentes curriculares que integram o referido curso. Dentre os achados, constatou-se uma invisibilidade da Cartografia no currículo, além de uma formação geográfica ínfima correspondendo a menos de $5 \%$ da carga horária total do curso, o que leva a concluir que a formação curricular, nessa Universidade, carece de um viés cartográfico associado às contribuições propiciadas pelos novos estudos do letramento.

PALAVRAS-CHAVE: LETRAMENTO; CARTOGRAFIA; CURRÍCULO; PEDAGOGIA.

\begin{abstract}
This article aims to investigate what proposes the curriculum of the Pedagogy course of a state university in relation to the cartographic literacy of the pedagogue. A qualitative approach is adopted and bibliographic and documentary research procedures are used. Altogether, it was possible to analyze 89 curricular components that are part of this course. Among the findings, it was found an invisibility of Cartography in the curriculum, in addition to a small geographical formation corresponding to less than $5 \%$ of the total course workload, leads him to conclude that the curricular training at this University lacks a cartographic bias associated with the contributions provided by the new studies of literacy.
\end{abstract}

KEYWORDS: LITERACY; CARTOGRAPHY; CURRICULUM; PEDAGOGY.

1 Universidade Estadual de Minas Gerais

2 Universidade Federal de Minas Gerais 


\section{RESUMEN}

Este artículo tiene como objetivo investigar lo que propone el currículo del curso de Pedagogía de una universidad estatal en relación con la alfabetización cartográfica del pedagogo. Se adopta un enfoque cualitativo y se utilizan procedimientos de investigación bibliográfica y documental. En total, fue posible analizar 89 componentes curriculares que forman parte de este curso. Entre los hallazgos, se encontró una invisibilidad de la Cartografía en el currículo, además de una pequeña formación geográfica correspondiente a menos del $5 \%$ de la carga de trabajo total del curso, le lleva a concluir que la formación curricular en esta Universidad carece de un sesgo cartográfico asociado a las contribuciones proporcionadas por los nuevos estudios de alfabetización.

\section{PALABRAS CLAVE: ALFABETIZACIÓN; CARTOGRAFÍA; REANUDAR; PEDAGOGÍA.}

\section{INTRODUÇÃO}

Este artigo busca investigar o que propõem os componentes curriculares integrantes do curso presencial de licenciatura em Pedagogia da Faculdade de Educação da Universidade do Estado de Minas Gerais, Campus de Belo Horizonte (FaE/UEMG-CBH) em relação ao aproveitamento das potencialidades dos novos estudos do letramento aplicados à formação cartográfica do pedagogo, profissional que, por ser habilitado para atuação no magistério da Educação Infantil (El), apresenta-se como a primeira referência da criança no processo inicial de construção do entendimento sobre o mundo e como a Geografia trabalha, lê e interpreta os fenômenos do espaço geográfico.

Isto porque a leitura da palavra é sempre precedida da leitura do mundo. E aprender a ler, a escrever, alfabetizar-se é, antes de mais nada, aprender a ler o mundo, compreender o seu contexto, não numa manipulação mecânica de palavras, mas numa relação dinâmica que vincula linguagem e realidade. Adernais, a aprendizagem da leitura e a alfabetização são atos de educação e educação é um ato fundamentalmente político. Paulo Freire reafirma a necessidade de que educadores e educandos se posicionem criticamente ao vivenciarem a educação, superando as posturas ingênuas ou "astutas", negando de vez a pretensa neutralidade da educação (FREIRE, 1989, p. 7).

Essa formação cartográfica do pedagogo associada aos novos estudos do letramento ancora-se numa perspectiva ampliada de alfabetização, ou seja, precede e ultrapassa, conforme Soares (1999), o domínio do sistema alfabético-ortográfico e da mecânica aprendizagem do ler e do escrever, pois refere-se ao "estado ou condição que adquire um grupo social ou um indivíduo como consequência de terse apropriado da escrita e de suas práticas" (SOARES, 1999, p.39). Esse estado ou 
condição dialoga com a definição de letramento proposta por Street $(2012$, p. 77$)$ com enfoque numa "concepção cultural mais ampla de modos particulares de pensar sobre a leitura e a escrita e de realizá-las em contextos culturais".

Nesse sentido, a leitura do mundo e a interpretação dos fenômenos geográficos acontece por um tipo específico de linguagem, a cartográfica, em que

[...] A leitura e a escrita, como linguagem, partem de um significado, cuja compreensão é essencial para que haja comunicação através do código escrito, a compreensão, por sua vez, envolve toda uma bagagem sóciocultural que o leitor deve possuir (ALMEIDA; PASSINI, 1999, p.31).

Por isso, ao pensarmos numa formação cartográfica ampliada do pedagogo, nos aproximamos de uma concepção de letramento geográfico e/ou cartográfico que se dá, conforme Street (2012), de forma situada e conexa aos contextos de variações socioculturais, o que demanda, segundo Moreira (2007, p. 68), a reinvenção da "[...] linguagem cartográfica como representação da realidade geográfica". Todavia, essa reinvenção implica antes numa questão curricular, cujos currículos estruturados segundo identidades imutáveis acabam por perder a flexibilidade diante dos movimentos do tempo, das diversidades e das multiculturalidades, visto que

Currículos que enquadram, que buscam incansavelmente a identidade, que "não engendram um personagem conceitual que valha a pena", são desinteressantes. Se não trazem novidades para quem os vive, são pouco importantes. Mais interessantes e são aqueles que desterritorializam, contagiam e provocam sensações: são os notáveis. Ser notável não é ser "correto", "simpático", "agradável". Mesmo antipático, repulsivo, um currículo pode ser notável, ter estilo, compor, fazer fugir, deixar a diferença fazer os seus jogos. Para deixar a diferença continuar o seu trabalho é preciso: possibilitar o acontecimento em um currículo! Deixar vazar! Fazer matilhas! Contagiar! Possibilitar um outro currículo; um currículo que pense com a diferença para ver, sentir e viver a vida em sua proliferação. Experimentar em um currículo: fazer currículo sem medo e sem programa. Arriscar! Com certas precauções, é claro, pois não podemos esquecer que a vida de muitos/as depende do currículo! Aventurar-se: aventurar junto com outras pessoas. Partilhar: coisas, afectos, sensações, desejos, aprendizagens [...] (PARAÍSO, 2010, p. 601-602).

Dessa forma, investigar a formação cartográfica do pedagogo perpassa pela compreensão das concepções evidenciadas nos novos estudos do letramento comparadas às noções implícitas e explícitas em documentos oficiais como as Diretrizes Curriculares Nacionais (DCN) e os Projetos Pedagógicos dos Cursos (PPC) que orientam a formação dos professores e disciplinam os cursos de graduação nas instituições de ensino superior (IES).

Segundo as disposições dos pareceres referentes às DCN, a formação do pedagogo precisa estar conexa às novas dinâmicas que interferem nos processos didático-formativos que delinearão o seu perfil enquanto educador, pelo que, 
permanecer alheio às mutações e inovações da realidade que já se vive, não permitirá, por exemplo, o aproveitamento das vantagens de aprendizagem possibilitadas por um tipo de "[...] alfabetização alterada e potencializada pelo ambiente digital [...]" (FRADE et. al., 2014). Assim, a inserção e o ensinamento de práticas de letramento digital no processo de formação cartográfica, além de ser uma função da escola, envolve a formação do pedagogo.

Ao considerarmos que a leitura do mundo e a interpretação dos fenômenos geográficos significa dominar o sistema sócio-semiótico que constitui a linguagem cartográfica, defendemos a hipótese de que dar significado aos significantes que possibilitam essa leitura e interpretação, perpassa, conforme Almeida e Passini (1999), pela indissociável formação do professor enquanto codificador e decodificador sociocultural desse sistema semiótico, sobretudo, quando se volta o olhar para a sociedade atual marcada pela cultura digital, em que a introdução das Tecnologias Digitais da Informação e Comunicação (TDICs) ao ensino da Cartografia "[...] potencializa o processo de aprendizagem dos recursos multimodais [...]" (FRADE et. al., 2014), emergindo perfis de leitor "imersivo" (SANTAELLA, 2004) e sujeito "participativo" (JENKINS, 2009), bem como, desestabilizando o conjunto de regras estáticas que distanciavam codificador (autor) e decodificador (leitor) e ensejando a transição do processo restrito de alfabetização cartográfica para uma perspectiva ampliada de letramento cartográfico digital.

Desse modo, tornar-se um leitor consciente cartográfico do mundo e dos seus fenômenos geográficos, presume-se ser também um codificador, pelo que, entendemos que o processo formativo de leitores cartográficos conscientes, num contexto de cultura digital, sustenta-se em práticas situadas de aprendizagens.

Diante do exposto, o corpus de estudo deste artigo constitui-se dos componentes curriculares do curso presencial de Licenciatura em Pedagogia da FaE/ UEMG-CBH.

\section{A CARTOGRAFIA ENQUANTO LEITURA DO MUNDO}

Neste artigo, leitura é um conceito-chave que constitui o objetivo apresentado - investigar o que propõem os componentes curriculares integrantes do curso presencial de licenciatura em Pedagogia da FaE/UEMG-CBH em relação ao aproveitamento das potencialidades dos novos estudos do letramento aplicados à formação cartográfica do pedagogo. Por isso, é importante demarcar inicialmente que, apesar de considerarmos a existência de variadas abordagens acerca do conceito de leitura e com elas dialogarmos, nos ancoramos nas literaturas histórico-cultural e geográfica para compreendermos um tipo específico de leitura, a cartográfica, a qual 
abrange desde gestos e modos dos sujeitos, a vivências e escolhas entre gêneros textuais por parte do leitor.

A leitura cartográfica insere-se no campo da semiótica (ou semiologia gráfica), cujo profissional do ramo, segundo Bertin (1980), denomina-se "redator gráfico", uma vez que, para esse autor, a Cartografia, como meio de representação da realidade, possui objetivos muito semelhantes à construção de um texto, dentre eles: definir critérios, categorizar e priorizar, pensar e entender para comunicar temas diversos com ou sem expressão física no espaço. Por sua vez, um dos objetos elementares da Cartografia é definido sob o nome de Mapa, considerado um texto politemático por natureza que, na concepção de Moreira (2007, p. 68):

É o repertório mais conspícuo do vocabulário geográfico. E trata-se da melhor representação do olhar geográfico. O mapa é a própria expressão da verdade de que todo fenômeno obedece ao princípio de organizar-se no espaço. Todo estudo ambiental, por exemplo, é o estudo de como a cadeia dos fenômenos arruma seu encadeamento na dimensão do ordenamento territorial, um fato que começa na localização, segue-se na distribuição e culmina na extensão por meio da qual se classifica como um ecossistema. Do contrário não haveria como. O mesmo acontece com o estudo de uma cidade, da vida do campo, da interação de montante e jusante da indústria, dos fluxos de redistribuição das formas de relevo, da alteração do desenho das bacias fluviais e das articulações do mercado. Eis porque o historiador trabalha com mapa, sem que tenha de ser geógrafo. Também o sociólogo. E igualmente o biólogo. Todos, mas necessariamente o geógrafo. O mapa é o fiel da sua identidade. Todo professor secundário sabe disso. E o mantém, e reforça. (MOREIRA, 2007, p. 68)

Nas palavras de Crampton e Krygier (2006, p. 15), "Mapas são ativos: eles constroem conhecimento ativamente, eles exercitam poder e eles podem ser". Enquanto significantes cartográficos ativos, os mapas dependem de "leitores críticos e, ao mesmo tempo, mapeadores conscientes" (SIMIELLI, 2002, p. 99), visto que, "o leitor que não conhece as regras e as convenções de produção das mídias de seu interesse está fadado a ser excluído [...]" (CARVALHO, 2007, p.20).

Com base nesses pressupostos, compreendemos leitura cartográfica conforme Bicalho et. al. (2014) e Coscarelli (2012) concebem leitura, ou seja, como uma complexa atividade de produção de sentido pelo leitor ao que é lido, que resulta do processo relacional entre as informações contidas no texto e os seus conhecimentos prévios, independente da forma material em que o texto se apresente, pelo que, não se restringe ao sistema morfológico, de estruturação e de formação de sílabas, palavras e parágrafos. A leitura é mais que decodificação desse sistema; constitui-se como um processo mental, de interação social e

Em suma, podemos dizer que a leitura lida inevitavelmente como muitos domínios cognitivos que devem se articular para viabilizar a construção de sentidos do texto. Esses domínios vão contribuir para a construção de cadeias referenciais para a produção de muitos tipos de inferências, para a 
construção da globalidade do texto e para a recuperação de inúmeros efeitos de sentido e intenções comunicativas. Por ser uma operação particular, que envolve a ativação e a articulação de inúmeras informações advindas de diferentes fontes, acreditamos e defendemos que a leitura de qualquer texto é, por natureza, hipertextual (COSCARELLI, 2012, p. 155).

Dessa forma, compreendemos que as atividades de leitura não são lineares e não se encerram na etapa de decodificação alfabética. Pelo contrário, ler significa mobilizar habilidades diversas que, juntas, carregam de sentidos e significados as estruturas textuais pelas quais corre o olhar labiríntico do leitor. Essa concepção se explica, em boa parte, pelos caminhos complexos, imprevisíveis e, por vezes, nebulosos trilhados pelo sujeito em seus atos de leitura que, conforme Chartier (1998), a emancipam das ordens e normas culturalmente reestabelecidas nos espaços e tempos diversos.

Segundo teóricos da perspectiva histórico-cultural, as práticas de leitura, os usos das materialidades e os valores que são conferidos a essas materialidades variam no tempo, no espaço e nas interações pessoais e sociais. Para Chartier (1998, p. 7):

A leitura é sempre apropriação, invenção, produção de significados. Segundo a bela imagem de Michel Certeau, o leitor é um caçador que percorre terras alheias. Aprendido pela leitura, o texto não tem de modo algum - ou ao menos totalmente - o sentido que Ihe atribui seu autor, seu editor ou seus comentadores. Toda história da leitura supõe, em seu princípio, esta liberdade do leitor que desloca e subverte aquilo que o livro lhe pretende impor. Mas esta liberdade leitora não é jamais absoluta. Ela é cercada por limitações derivadas das capacidades, convenções e hábitos que caracterizam, em suas diferenças, as práticas de leitura. Os gestos mudam segundo os tempos e lugares, os objetos lidos e as razões de ler. Novas atitudes são inventadas, outras se extinguem compreensão. (CHARTIER, 1998, p.7)

Essa concepção de leitura vinculada aos aspectos socioculturais e semióticos, defendida por Chartier (1998), significa um novo olhar para as práticas de leitura e escrita de forma associada às dimensões socioculturais percebidas nos sucessivos eventos de letramento, os quais ganham importância por capacitarem "[...] pesquisadores, e também praticantes, a focalizar uma situação particular onde as coisas estão acontecendo e pode-se vê-las enquanto acontecem" (STREET, 2012, p. 75).

Assim, o conhecimento dos modos de ler e escrever que se operam nos atos de leitura e escrita revela esses eventos, cuja tomada de consciência dos mesmos, consequentemente, permitirá configurar as práticas de leitura e escrita situadas nos diferentes espaços e tempos socioculturais que são materializadas pelas vivências humanas, o que ratifica o termo letramento como um processo em que, segundo Ferreiro (1985), a aprendizagem da leitura e da escrita ocorre pela apropriação 
do conhecimento desse aprender, através da reconstrução do modo como ele é produzido. Isso quer dizer que é preciso reinventar a escrita.

Essa apropriação, que se dá pela ligação desses modos de leitura e escrita com a cultura, é imprescindível para a produção de sentidos por parte do leitor àquilo que materialmente está à sua vista e é carregado de conteúdo a ser decifrado. Essa forma de materialidade, ou seja, o gênero textual que a representa, por sua vez, também é um influenciador da maneira pela qual o leitor dele se apropriará. A esse respeito, do ponto de vista da leitura cartográfica, no caso do mapa temático, um gênero cartográfico que se expressa por sua multimodalidade, em que a comunicação é atemporal e não linear, a produção de sentido, pelo leitor, ao que salta aos seus olhos, demanda posturas de leitura descontínuas. Por essa especificidade, a leitura cartográfica, por sua atemporalidade e não linearidade, incide num tipo complexo de leitura, cuja produção de sentido ao que é lido depende da interação subjetiva entre leitor e texto, aqui entendido também como mapa, uma vez que,

[...] o ato de ler é variável, não absoluto. Em sua definição moderna mais ampla, a leitura é como se sabe, 'a capacidade de extrair sentido de símbolos escritos ou impressos'. O leitor 'emprega os símbolos para orientar a recuperação de informações de sua memória e, em seguida, cria, com essas informações, uma interpretação plausível da mensagem do escritor'. Entretanto, nem sempre a leitura foi definida desse modo. No início, ela consistia na mera capacidade de obtenção de informações visuais com base em algum sistema codificado, bem como na concepção de seu significado. Mais tarde, passou a significar, quase de modo exclusivo, a compreensão de um texto contínuo com sinais escritos sobre uma superfície gravada. Mais recentemente, incluiu também a extração de informações codificadas de uma tela eletrônica. $E$ a definição de leitura continuará, por certo, a se expandir no futuro porque, assim como qualquer outra aptidão, ela também é um indicador do avanço da própria humanidade (FISCHER, 2006, p 11).

A história conceitual da leitura a investe de uma complexidade plural considerando que "ao trilhar diferentes caminhos de leitura, as pessoas extraem diferentes sentidos do texto" (BARTON, 2007, p. 49), em que cada gênero textual, a exemplo do mapa temático, possui um objetivo específico intencionalmente definido por seu elaborador. Enquanto gênero textual, o mapa temático deve cumprir a função prioritária de conceituar, localizar e explicar os processos que envolvem determinado fenômeno geográfico ao leitor, valendo-se de signos selecionados de forma a facilitar as correlações entre o leitor, o texto e as intenções do seu elaborador, visto que

A leitura do mundo se faz por intermédio das categorias da localização e da distribuição, mesmo que o problema do primado da primeira sobre a segunda, as categorias da distribuição e da extensão entrando para o fim da montagem do discurso do geográfico como a unidade espacial dos fenômenos. Aí ainda aprendemos o ritual banal do trabalho geográfico: localizando-se e distribuindo-se é que se mapeia o mundo. E que todo trabalho geográfico consiste na seqüência clássica: primeiro localiza-se o fenômeno; depois monta-se a rede da sua distribuição; a seguir demarca- 
se a extensão; por fim, transporta-se a leitura para a sua representação cartográfica. Mas tudo sendo verbalizado, ainda, na linguagem do mapa (MOREIRA, 2007, p. 67-68).

Na concepção de Kress e Bezemer (2009), o produtor de textos, ou seja, o autor, possui um duplo interesse que se relaciona com a representação (qual o melhor signo que traduziria o que ele quer representar) e com a comunicação (qual a melhor forma de alcançar o público), pois o seu produto, o texto e/ou o mapa, está associado com dimensões sociais, históricas, culturais, políticas, econômicas, ambientais e tecnológicas, pelas quais os signos são pensados e elaborados. Esses signos carregam, por essa acepção, múltiplas dimensões, demonstrando que

As articulações entre os modos semióticos têm mudado tanto em relação à função, pois são considerados veículos de informação, deixando a imagem de ser apenas ilustração da escrita. As práticas de letramento não se restringem mais ao sistema linguístico, visto que o letramento é um processo social que permeia nossas rotinas diárias numa sociedade extremamente semiotizada [...] (DIONÍSIO; VASCONCELOS, 2013, p. 34).

Essas novas articulações ampliaram, assim, tanto o conceito de letramento para além de uma concepção restrita de alfabetização, inserindo-o no campo dos multiletramentos, quanto o de gênero textual, dado que outros modos, como a imagem, potencializaram-se enquanto formas de comunicação.

Entretanto, a Cartografia que, segundo Moreira (2007, p. 65), constitui-se como a forma que a Geografia lê o mundo, "deixou de atualizar-se já de um tempo. As expressões vocabulares antigas perderam a atualidade, diante dos novos conteúdos, e as expressões novas foram tiradas mais de outros campos de saber, que da sua própria evolução histórica".

No caso específico do mapa temático, dada a sua inerente característica híbrida de linguagem, em que a imagem é o modo de comunicação que prevalece e cujo potencial de significação está na intensificado das articulações semióticas harmoniosas entre símbolos, letras, cores, tamanhos, granulações, orientações e formas, no contexto contemporâneo marcado pela "cultura digital" (MANEVY, 2009), ele passou a agregar novos conceitos vinculados à intensificação da "tecnologia" (PINTO, 2005), em que as informações, antes limitadas ao papel, são convertidas para o meio digital, potencializando essa forma peculiar de representar, ler e interpretar o mundo por meio da imagem e dos signos variados. 


\section{O TERRITÓRIO3 DA CARTOGRAFIA DO CURSO INVESTIGADO}

A partir desse referencial teórico, procedemos à análise curricular do curso presencial de licenciatura em Pedagogia da FaE/UEMG-CBH, que integra os 115 (cento e quinze) cursos de graduação da UEMG ofertados na modalidade presencial.

Para o desenvolvimento desta análise curricular, que se caracteriza como qualitativa, nos valemos, com base em Bogdan e Biklen (1994), de dois procedimentos: a pesquisa bibliográfica e a pesquisa documental.

Na revisão de literatura, com base em Gil (2002, p. 50), segundo o qual "a pesquisa bibliográfica é desenvolvida mediante material já elaborado, principalmente livros e artigos científicos [...]", recorremos a livros e artigos de teóricos que nos permitiram um olhar ampliado sobre currículo e a importância da formação cartográfica do Pedagogo face ao aproveitamento das contribuições de teóricos como: Almeida e Passini (1999), Arroyo (2011), Barton (2007), Bertin (1980), Bicalho et. al. (2014), Carvalho (2007), Chartier (1998), Coscarelli (2012), Crampton e Krygier (2006), Dionísio e Vasconcelos (2013), Ferreiro (1985), Fischer (2006), Frade et. al. (2014), Freire (1989), Gatti e Nunes (2009), Jenkins (2009), Kenski (2012), Kress e Bezemer (2009), Manevy (2009), Moreira (2007), Paraíso (2010), Pinto (2005). Santaella (2004), Simielli (2002), Soares (1999; 2014) e Street (2012),

Para a pesquisa documental, também inspirados em Gil (2002, p. 46), para o qual "[...] na pesquisa documental, as fontes são muito mais diversificadas e dispersas", consultamos legislações e documentos normativos diversos sobre a formação do pedagogo, a história do curso e da instituição investigados e, principalmente, o Projeto Pedagógico do Curso (PPC) presencial de licenciatura em Pedagogia da FaE/UEMG$\mathrm{CBH}^{4}$.

Esse curso pertence à UEMG, uma entidade autárquica dotada de personalidade jurídica de direito público interno e regime especial de ensino, pesquisa e extensão, de caráter multicampi, criada pelo Art.81 do Ato das Disposições Constitucionais Transitórias da Constituição Mineira de 1989, combinado com o parágrafo primeiro do Art.82, do mesmo Ato, que tem como missão: "Promover o

\footnotetext{
3 A categoria território é aqui entendida à luz de Raffestin (1987; 1993), segundo o qual, o território não se traduz meramente num espaço físico objetivo qualquer, pelo contrário, nele se desvelam as relações intersubjetivas que se materializam na (re)construção social do conhecimento. Essas relações são prenhes de poder, ideologias, embates, conflitos, rupturas, continuidades que se vinculam às dimensões sociais, políticas, históricas, econômicas, culturais, ambientais e tecnológicas, as quais estão presentes no processo de ensino e de aprendizagem, ou seja, são inerentes ao processo de escolarização.
}

4 Encontra-se reconhecido pela Resolução SEDCTES nº. 09/2018, publicada em 06 de março de 2018, tem como finalidade principal formar profissionais para atuarem na docência da El e dos anos iniciais do ensino fundamental e subsidiariamente nas atividades de gestão, planejamento, pesquisa, coordenação e avaliação da ação educativa em espaços escolares e não escolares. 
Ensino, a Pesquisa e a Extensão de modo a contribuir para a formação de cidadãos comprometidos com o desenvolvimento e a integração dos setores da sociedade e das regiões do estado" (UEMG, 2014).

Segundo dados extraídos do seu site institucional, atualmente a UEMG conta com 118 (cento e dezoito) cursos de graduação dos tipos bacharelado, licenciatura e tecnólogo na modalidade presencial, 03 (três) na modalidade a distância, 10 (dez cursos) de pós-graduação Stricto Sensu, sendo oito mestrados e dois doutorados, além de 27 (vinte e sete) cursos de especialização, Lato Sensu, distribuídos em diversas áreas de conhecimento. A esses cursos estão vinculados 1.647 (mil seiscentos e quarenta e sete) docentes e 21.644 (vinte e um mil seiscentos e quarenta e quatro) estudantes de graduação, sendo $77 \%$ (setenta e sete) oriundos da rede pública de ensino do Brasil, e 652 (seiscentos e cinquenta e dois) estudantes de pós-graduação.

O curso presencial de Licenciatura em Pedagogia da FaE/UEMG-CBH teve origem no Instituto de Educação de Minas Gerais (IEMG) onde funcionou durante 25 (vinte e cinco) anos e foi incorporado à FaE/UEMG-CBH no ano de 1994 por força da Lei $n^{\circ} 11.539$, de 22 de julho de 1994:

\begin{abstract}
Art. 24 - Ficam incorporadas à Universidade as seguintes entidades: I Fundação Mineira de Arte Aleijadinho - FUMA -, de Belo Horizonte; II Fundação Escola Guignard, de Belo Horizonte; III - Curso de Pedagogia do Instituto de Educação de Minas Gerais, de Belo Horizonte; IV - Serviço de Orientação e Seleção Profissional - SOSP -, de Belo Horizonte, criado pela Lei $n^{\circ} 482$, de 11 de novembro de 1949 [...] Art. 27 - Fica transferido para a UEMG o patrimônio móvel do Curso de Pedagogia do Instituto de Educação de Minas Gerais (GOVERNO DE MINAS GERAIS, 1994).
\end{abstract}

Com um formato curricular aprovado em fevereiro de 1998, adaptado no ano de 2008, tendo passado por novas reformulações pontuais em 2010, notadamente as alterações aprovadas no COEPE/UEMG em 23 de novembro de 2010 que the deu uma nova configuração, estando em processo de reformulação desde o ano de 2011, o currículo do curso presencial de Licenciatura em Pedagogia da FaE/UEMG$\mathrm{CBH}$ estrutura-se em oito núcleos formativos semestrais (NF), que compreendem 89 (oitenta e nove) componentes curriculares orientados segundo oito eixos formativos. Possui uma carga horária total de 4.432 (quatro mil, quatrocentos e trinta e duas) horas, sendo distribuídas em 3.456 (três mil, quatrocentos e cinquenta e seis) horas em disciplinas e 976 (novecentos e setenta e seis) horas em Práticas Pedagógicas de Formação (PPF's). Oferta 120 (cento e vinte) vagas semestrais nos turnos matutino, vespertino e noturno, cujas formas de ingresso adotadas, desde o ano de 2020, são ENEN/SiSU, Transferência Externa e Obtenção de Novo Título. Atualmente o curso abrange um universo de 860 (oitocentos e sessenta) discentes. Para tanto, apresentamos o quadro curricular abaixo: 


\section{Quadro 1 - Matriz curricular do Curso de Pedagogia da FaE/UEMG-CBH}

\begin{tabular}{|c|c|c|c|}
\hline \multicolumn{4}{|c|}{ Núcleo formativo: 1} \\
\hline \multicolumn{4}{|c|}{ Eixo: Contextos Sociais, Culturais e Educacionais } \\
\hline Código $^{5}$ & Componente curricular & Natureza & $\mathrm{CH}^{6}$ \\
\hline DAE0017 & Pedagogia e sua Multidimensionalidade & $\mathrm{OB}^{8}$ & 54 \\
\hline DFSHFE0029 & História da Educação: Educação na Formação Social Moderna & OB & 54 \\
\hline DFSHFE003 & Estudos Filosóficos: Sociedade e Educação & OB & 54 \\
\hline DPEMP004 $4^{10}$ & Psicologia da Educação: Teorias Psicológicas e Práticas Educativas & OB & 54 \\
\hline DFSHFE005 & Sociologia: Sociedade e Educação & OB & 54 \\
\hline DMTE006 11 & $\begin{array}{l}\text { Didática: Pensamento Educacional e Processo de Ensino- } \\
\text { Aprendizagem na Educação }\end{array}$ & OB & 72 \\
\hline DMTE007 & Língua Portuguesa & OB & 36 \\
\hline DPEMP008 & Pesquisa em Educação & OB & 36 \\
\hline PPF00912 & Atividade de Integração Pedagógica - AIP & PPF & 36 \\
\hline \multicolumn{4}{|c|}{ Núcleo formativo: 2} \\
\hline \multicolumn{4}{|c|}{ Eixo: O Sujeito e os contextos sociais, culturais e educacionais } \\
\hline Código & Componente curricular & Natureza & $\mathrm{CH}$ \\
\hline DFSHFE010 & $\begin{array}{l}\text { História da Educação: Educação na Formação Social Moderna e na } \\
\text { Sociedade Brasileira }\end{array}$ & OB & 72 \\
\hline DFSHFE011 & Estudos Filosóficos: Epistemologias da Educação & OB & 72 \\
\hline DFSHFE012 & Sociologia: Sociedade e Educação & OB & 54 \\
\hline DPEMP013 & Psicologia da Educação para a Educação Infantil & OB & 72 \\
\hline DFSHFE014 & Antropologia: Cultura, Sociedade e Educação & OB & 54 \\
\hline DMTE015 & $\begin{array}{l}\text { Didática: Processos de Aprendizagem na Educação Infantil e nos Anos } \\
\text { Inicias do Ensino Fundamental }\end{array}$ & OB & 54 \\
\hline DMTE016 & Educação e Tecnologia: Sociedade da Informação e do Conhecimento & OB & 36 \\
\hline DPEMP017 & Pesquisa em Educação & OB & 36 \\
\hline PPF018 & Atividade de Integração Pedagógica - AIP & PPF & 36 \\
\hline PPF019 & Estágio Supervisionado & PPF & 30 \\
\hline PPF020 & Práticas Pedagógicas & PPF & 15 \\
\hline
\end{tabular}

5 Com a finalidade de facilitarmos a compreensão das análises, atribuímos códigos para as respectivas disciplinas que integram o currículo do curso presencial de licenciatura em Pedagogia da FaE/UEMG-CBH. Esses códigos adotaram como padrão a sigla do departamento acadêmico no qual estão alocadas as disciplinas/componentes curriculares seguida de números sequenciais crescentes de acordo com a ordenação em que se apresentam nos oito núcleos formativos, iniciando-se em 001.

6 Carga horária.

7 Departamento de Administração Educacional.

8 Disciplina - obrigatória.

9 Departamento de Fundamentos Sócio-Históricos e Filosóficos da Educação.

10 Departamento de Psicologia da Educação e Metodologia de Pesquisa.

11 Departamento de Métodos e Técnicas de Ensino.

12 Prática Pedagógica de Formação. 


\begin{tabular}{|c|c|c|c|}
\hline \multicolumn{4}{|c|}{ Núcleo formativo: 3} \\
\hline \multicolumn{4}{|c|}{$\begin{array}{l}\text { Eixo: O sujeito e as práticas educativas na Educação Infantil e nos Anos Iniciais do Ensino } \\
\text { Fundamental }\end{array}$} \\
\hline Código & Componente curricular & Natureza & $\mathrm{CH}$ \\
\hline DFSHFE021 & $\begin{array}{c}\text { História da Educação: Bases Sociais, Políticas do Pensamento } \\
\text { Educacional Brasileiro }\end{array}$ & OB & 54 \\
\hline DFSHFE022 & Antropologia: Cultura Brasileira & OB & 54 \\
\hline DPEMP023 & Psicologia da Educação para os Anos Iniciais do Ensino Fundamental & OB & 54 \\
\hline DMTE024 & $\begin{array}{l}\text { Estudos dos Conteúdos - Ciências da Natureza: Desenvolvimento da } \\
\text { Criança na Educação infantil e Anos Iniciais do Ensino Fundamental }\end{array}$ & OB & 54 \\
\hline DMTE025 & Didática: Planejamento e Avaliação no Processo Pedagógico & OB & 72 \\
\hline DAE026 & Organização Curricular da Educação Básica & OB & 72 \\
\hline DPEMP027 & Estudos sobre Estatística Aplicada à Educação & OB & 54 \\
\hline DPEMP028 & Pesquisa em Educação & OB & 36 \\
\hline PPF029 & Atividade de Integração Pedagógica - AIP & PPF & 36 \\
\hline PPF030 & Estágio Supervisionado & PPF & 36 \\
\hline PPF031 & Práticas Pedagógicas & PPF & 20 \\
\hline \multicolumn{4}{|c|}{ Núcleo formativo: 4} \\
\hline \multicolumn{4}{|c|}{$\begin{array}{l}\text { Eixo: O sujeito e as práticas educativas na Educação Infantil e nos Anos Iniciais do Ensino } \\
\text { Fundamental }\end{array}$} \\
\hline Código & Componente curricular & Natureza & $\mathrm{CH}$ \\
\hline DPEMP032 & Psicologia da Educação para a Educação de Jovens e Adultos & OB & 54 \\
\hline DMTE033 & $\begin{array}{l}\text { Língua Portuguesa: Conteúdos e Metodologias na Educação Infantil e } \\
\text { nos Anos Iniciais do Ensino Fundamental }\end{array}$ & OB & 72 \\
\hline DMTE034 & $\begin{array}{l}\text { Matemática: Conteúdos e Metodologias na Educação Infantil e nos } \\
\text { Anos Iniciais do Ensino Fundamental }\end{array}$ & OB & 72 \\
\hline DMTE035 & $\begin{array}{l}\text { Geografia e História: Conteúdos e Metodologias na Educação Infantil e } \\
\text { nos Anos Iniciais do Ensino Fundamental }\end{array}$ & OB & 72 \\
\hline DMTE036 & $\begin{array}{c}\text { Ciências da Natureza: Conteúdos e Metodologias na Educação Infantil } \\
\text { e nos Anos Iniciais do Ensino Fundamental }\end{array}$ & OB & 72 \\
\hline DMTE037 & $\begin{array}{l}\text { Educação Física: Conteúdos e Metodologias na Educação Infantil e nos } \\
\qquad \text { Anos Iniciais do Ensino Fundamental }\end{array}$ & OB & 72 \\
\hline DPEMP038 & Pesquisa em Educação & OB & 36 \\
\hline PPF039 & Atividade de Integração Pedagógica - AIP & PPF & 36 \\
\hline PPF040 & Estágio Supervisionado & PPF & 36 \\
\hline PPF041 & Práticas Pedagógicas & PPF & 20 \\
\hline \multicolumn{4}{|c|}{ Núcleo formativo: 5} \\
\hline \multicolumn{4}{|c|}{$\begin{array}{l}\text { Eixo: Políticas, Gestão Educacional e Práticas Educativas na Educação Infantil e nos Anos Iniciais } \\
\text { do Ensino Fundamental }\end{array}$} \\
\hline Código & Componente curricular & Natureza & $\mathrm{CH}$ \\
\hline DAE042 & Pedagogia e sua Multidimensionalidade & OB & 54 \\
\hline DAE043 & Organização Curricular da Educação Básica & OB & 72 \\
\hline DMTE044 & $\begin{array}{l}\text { Língua Portuguesa: Conteúdos e Metodologias na Educação Infantil e } \\
\text { nos Anos Iniciais do Ensino Fundamental }\end{array}$ & OB & 72 \\
\hline
\end{tabular}




\begin{tabular}{|c|c|c|c|}
\hline DMTE045 & $\begin{array}{l}\text { Matemática: Conteúdos e Metodologias na Educação Infantil e nos } \\
\text { Anos Iniciais do Ensino Fundamental }\end{array}$ & OB & 72 \\
\hline DAE046 & $\begin{array}{c}\text { Organização e Funcionamento do Sistema Educacional - Educação } \\
\text { Básica }\end{array}$ & OB & 54 \\
\hline DAE047 & Gestão da Escola na Educação Básica & OB & 72 \\
\hline DPEMP048 & Pesquisa em Educação & OB & 54 \\
\hline PPF049 & Atividade de Integração Pedagógica - AIP & PPF & 36 \\
\hline PPF050 & Estágio Supervisionado & PPF & 36 \\
\hline PPF051 & Prática de Pesquisa & PPF & 20 \\
\hline PPF052 & Práticas Pedagógicas & PPF & 25 \\
\hline \multicolumn{4}{|c|}{ Núcleo formativo: 6} \\
\hline \multicolumn{4}{|c|}{ Eixo: Práticas Educativas na Educação Infantil e nos Anos Iniciais do Ensino Fundamental } \\
\hline Código & Componente curricular & Natureza & $\mathrm{CH}$ \\
\hline DMTE053 & Estudos Sobre Necessidades Educacionais Especiais & OB & 72 \\
\hline DMTE054 & $\begin{array}{l}\text { Arte na Educação: Conteúdos e Metodologias na Educação Infantil e } \\
\text { nos Anos Iniciais do Ensino Fundamental }\end{array}$ & OB & 54 \\
\hline DMTE055 & $\begin{array}{l}\text { Língua Portuguesa: Conteúdos e Metodologias na Educação Infantil e } \\
\text { nos Anos Iniciais do Ensino Fundamental }\end{array}$ & OB & 72 \\
\hline DMTE056 & $\begin{array}{l}\text { Matemática: Conteúdos e Metodologias na Educação Infantil e nos } \\
\text { Anos Iniciais do Ensino Fundamental }\end{array}$ & OB & 72 \\
\hline DMTE057 & $\begin{array}{l}\text { Geografia e História: Conteúdos e Metodologias na Educação Infantil e } \\
\text { nos Anos Iniciais do Ensino Fundamental }\end{array}$ & OB & 54 \\
\hline DMTE058 & $\begin{array}{c}\text { Ciências da Natureza: Conteúdos e Metodologias na Educação Infantil } \\
\text { e nos Anos Iniciais do Ensino Fundamental }\end{array}$ & OB & 54 \\
\hline DMTE059 & Educação e Tecnologia: Mediação Tecnológica & OB & 36 \\
\hline PPF060 & Atividade de Integração Pedagógica - AIP & PPF & 36 \\
\hline PPF061 & $\begin{array}{l}\text { Estágio Supervisionado (Educação Infantil 24h/a + Anos Iniciais do } \\
\text { Ensino Fundamental e/ou Educação de Jovens e Adultos - 60h/a) }\end{array}$ & PPF & 84 \\
\hline PPF062 & Prática de Pesquisa & PPF & 20 \\
\hline PPF063 & Práticas Pedagógicas & PPF & 20 \\
\hline PPF064 & Trabalho de Conclusão de Curso: Elaboração de Monografia & PPF & 36 \\
\hline \multicolumn{4}{|c|}{ Núcleo formativo: 7} \\
\hline \multicolumn{4}{|c|}{ Eixo: Práticas Educativas na Educação Infantil e nos Anos Iniciais do Ensino Fundamental } \\
\hline Código & Componente curricular & Natureza & $\mathrm{CH}$ \\
\hline DFSHFE065 & Estudos Filosóficos: Ética na Formação do Educador & OB & 54 \\
\hline DFSHFE066 & $\begin{array}{c}\text { Organização Social e Técnica do Trabalho Capitalista: Profissão } \\
\text { Docente }\end{array}$ & OB & 54 \\
\hline DMTE067 & $\begin{array}{l}\text { Arte: Conteúdos e Metodologias na Educação Infantil e nos Anos } \\
\qquad \text { Iniciais do Ensino Fundamental }\end{array}$ & OB & 54 \\
\hline DMTE068 & $\begin{array}{l}\text { Matemática: Conteúdos e Metodologias na Educação Infantil e nos } \\
\text { Anos Iniciais do Ensino Fundamental }\end{array}$ & OB & 54 \\
\hline DAE069 & Sala de Aula: Espaço Social, Cultural e Histórico & OB & 54 \\
\hline DMTE070 & $\begin{array}{l}\text { Educação Física: Conteúdos e Metodologias na Educação Infantil e nos } \\
\qquad \text { Anos Iniciais do Ensino Fundamental }\end{array}$ & OB & 54 \\
\hline DMTE071 & Introdução à Língua Brasileira de Sinais - LIBRAS & OB & 54 \\
\hline
\end{tabular}




\begin{tabular}{|c|c|c|c|}
\hline DMTE072 & Educação e Tecnologia: Mídias e Educação & OB & 36 \\
\hline PPF073 & Atividade de Integração Pedagógica - AIP & PPF & 36 \\
\hline PPF074 & $\begin{array}{l}\text { Estágio Supervisionado (Educação Infantil 24h/a + Anos Iniciais do } \\
\qquad \text { Ensino Fundamental }-60 \mathrm{~h} / \mathrm{a})\end{array}$ & PPF & 84 \\
\hline PPF075 & Prática de Pesquisa & PPF & 20 \\
\hline PPF076 & Práticas Pedagógicas & PPF & 20 \\
\hline PPF077 & Trabalho de Conclusão de Curso: Elaboração de & PPF & 36 \\
\hline \multicolumn{4}{|c|}{ Núcleo formativo: 8} \\
\hline \multicolumn{4}{|c|}{$\begin{array}{l}\text { Eixo: Políticas, Gestão Educacional e Práticas Educativas na Educação Infantil e nos Anos Iniciais } \\
\text { do Ensino Fundamental }\end{array}$} \\
\hline Código & Componente curricular & Natureza & $\mathrm{CH}$ \\
\hline DAE078 & $\begin{array}{l}\text { Organização e Funcionamento do Sistema Educacional: Educação } \\
\text { Básica }\end{array}$ & OB & 72 \\
\hline DMTE079 & $\begin{array}{l}\text { Língua Portuguesa: Conteúdos e Metodologias na Educação Infantil e } \\
\text { nos Anos Iniciais do Ensino Fundamental }\end{array}$ & OB & 54 \\
\hline DAE080 & Gestão da Escola na Educação Básica & OB & 72 \\
\hline DMTE081 & $\begin{array}{l}\text { Geografia e História: Conteúdos e Metodologias na Educação Infantil e } \\
\text { nos Anos Iniciais do Ensino Fundamental }\end{array}$ & OB & 54 \\
\hline DAE082 & Avaliação Educacional - Sistemas e Instituições & OB & 54 \\
\hline DAE083 & Políticas Públicas para a Educação Básica & $\mathrm{OB}$ & 72 \\
\hline DMTE084 & Educação e Tecnologia: Informática Educativa & OB & 36 \\
\hline PPF085 & Atividade de Integração Pedagógica - AIP & PPF & 36 \\
\hline PPF086 & $\begin{array}{l}\text { Estágio Supervisionado (Educação Infantil 30h/a + Anos Iniciais do } \\
\qquad \text { Ensino Fundamental - 24h/a) }\end{array}$ & PPF & 54 \\
\hline PPF087 & Prática de Pesquisa & PPF & 20 \\
\hline PPF088 & Práticas Pedagógicas & PPF & 20 \\
\hline PPF089 & Trabalho de Conclusão de Curso: Elaboração de Monografia & PPF & 36 \\
\hline \multicolumn{3}{|c|}{ Carga horária total } & 3.465 \\
\hline
\end{tabular}

Fonte: Elaborado do autor a partir do PPC do currículo de Pedagogia da FaE/UEMG$\mathrm{CBH}, 2019$.

O currículo compreende 89 (oitenta e nove) componentes curriculares obrigatórios divididos em disciplinas e PPF's. Essas Práticas Pedagógicas de Formação configuram-se nos oito NF, correspondem aos componentes curriculares Atividade de Integração Pedagógica (288 horas aula), Estágio Supervisionado (300 horas aula), Trabalho de Conclusão de Curso e Práticas de Pesquisa (80 horas aula) e Pedagógicas (140 horas aula) fora do horário das aulas, o que totaliza uma carga horária de 976 (novecentos e setenta e seis) horas aula.

Das 3.456 (três mil, quatrocentos e cinquenta e seis) horas aula de disciplinas e 976 (novecentos e setenta e seis) horas aula de PPF's, é importante destacar que, do segundo ao oitavo NF ocorre o ministério de disciplinas de modo integrado, ou 
seja, dois professores se articulam e reservam uma aula da sua disciplina para ser ministrada em conjunto com outra que integra o mesmo NF.

Outro aspecto relevante diz respeito ao componente curricular denominado Atividade de Integração Pedagógica (AIP), que está presente em todos os NF; os componentes curriculares Estágio Supervisionado e Práticas Pedagógicas compreendem do segundo ao oitavo NF; o componente curricular Práticas de Pesquisa está pressente do quinto ao oitavo NF; e o componente curricular Trabalho de Conclusão de Curso (TCC) compreende os três últimos NF.

No que concerne aos estudos do campo da linguagem cartográfica, foco desta análise curricular, depreende-se do PPC que há uma perspectiva explícita para a preparação do pedagogo concernente à capacitação, competência e habilidade de

\begin{abstract}
Relacionar as linguagens dos meios de comunicação à educação, nos processos didático-pedagógicos, demonstrando domínio das tecnologias de informação e comunicação adequadas ao desenvolvimento de aprendizagens significativas [...] compreensão e valorização das diferentes linguagens e padrões culturais manifestados na sociedade contemporânea e de sua função na produção do conhecimento (UEMG, 2008, p. 15-16).
\end{abstract}

Entretanto, constatamos que esse campo de estudo e seus termos correlatos derivados (leitura, escrita e letramento) se restringem à disciplina de Língua Portuguesa (DMTE007, DMTE033, DMTE044, DMTE055, DMTE079) e se configuram em 07 (sete) dos 89 (oitenta e nove) componentes curriculares que integram o currículo do curso presencial de licenciatura em Pedagogia da FaE/UEMG-CBH. Atenta-se que, excepcionalmente, o termo "letramento" aparece em uma bibliografia básica da disciplina de Matemática do NF 7 (DMTE068) e o termo "linguagem" se apresenta na ementa de uma disciplina, também do mesmo NF, porém, vinculada ao DAE (DAE069). Ou seja, incoerentemente os termos "linguagem", "leitura", "escrita" e "letramento" não se configuram em nenhuma das disciplinas e/ou componentes curriculares da área de conhecimento da Geografia, ciência que tem a linguagem cartográfica como principal forma de ler o mundo, segundo Moreira (2007).

Para realizarmos a análise da formação cartográfica no currículo vigente do curso presencial de Licenciatura em Pedagogia da FaE/UEMG-CBH, valemo-nos da categorização curricular fixada no artigo $6^{\circ}$ da Resolução CNE/CP N 1 , de 15 de maio de 2006, assim definidos: Núcleo de estudos básicos, Núcleo de aprofundamento e diversificação de estudos e Núcleo de estudos integradores.

Com base nessas definições categóricas e a partir da constatação de que os termos "linguagem", "leitura", "escrita" e "letramento" não se referem a nenhum dos componentes curriculares relacionados à área de conhecimento da Geografia, 
passamos a analisar as nomenclaturas, ementas ${ }^{13}$ e bibliografias básicas dos componentes curriculares com base em 09 (nove) palavras-chave e seus derivados relacionados com a temática principal: "geografia", "espaço geográfico", "representação do espaço", "mapa", "multiletramento", "multimodalidade", "semiótica", "semiologia" e "cartografia". As análises resultaram das seguintes questões centrais: Que formação cartográfica (para qual tempo e espaço) proclama o currículo do curso presencial de Licenciatura em Pedagogia da FaE/UEMG-CBH? Essa formação está conectada com a cultura digital?

Foi possível examinar $89^{14}$ (oitenta e nove) componentes curriculares. A leitura das nomenclaturas, ementas e bibliografias básicas permitiu identificar que o termo "geografia" compreende 03 (três) componentes curriculares presentes nos NF 4, 6 e 8: DMTE035, DMTE057 e DMTE081.

Com relação aos termos "espaço geográfico", "representação do espaço", "mapa", "multiletramento", "multimodalidade", "semiótica", "semiologia" e "cartografia", esses não compõem a nomenclatura de nenhum dos componentes integrantes do currículo. Esses termos, também, com exceção de "espaço geográfico" e "representação do espaço" que configuram na bibliografia básica da disciplina DMTE057, não aparecem nas ementas e bibliografias básicas de nenhum dos componentes curriculares que integram o curso investigado.

Para investigarmos se as bibliografias básicas da totalidade dos componentes curriculares que integram o currículo do curso presencial de licenciatura em Pedagogia da FaE/UEMG-CBH contemplam a formação cartográfica do pedagogo, utilizamos os supracitados termos descritores, cuja sistematização bibliográfica apresentamos revelou alguns aspectos preocupantes: apenas 01 (um) - DMTE057 - dos apenas 03 (três) componentes curriculares que supostamente contemplam a formação cartográfica do pedagogo da FaE/UEMG-CBH, possui base teórica relacionada, entretanto, desatualizada; a concomitante formação em Geografia e História revelase insuficiente em termos de qualidade e quantidade; nenhum dos representantes dos novos estudos do letramento são contemplados nas bibliografias básicas, inclusive nos causa estranheza que teóricos clássicos e contemporâneos da ciência geográfica e notadamente da Cartografia não são contemplados em nenhuma das bibliografias básica dos componentes curriculares analisados; e não constatamos nenhuma base

13 "Ementa é o resumo que facilita o acesso de alunos e demais interessados às intenções de um determinado curso, sua redação mereceria ser mais cuidadosa" (GATTI; NUNES, 2009, p. 32).

14 Os componentes curriculares de PPF's, num total de 29 (vinte e nove), não possuem ementas e bibliografias básicas fixadas no PPC como no caso das disciplinas de natureza obrigatória, devido a isso, a análise se restringiu às nomenclatura e definição dos mesmos. 
teórica que contemple a formação geográfica e/ou cartográfica inserida na cultura digital marcante no tempo presente.

Esses aspectos evidenciam uma possível incoerência qualitativa nos componentes curriculares no que diz respeito à consonância entre nomenclatura, ementa, bibliografia básica e o perfil de pedagogo que se quer formar com base nas capacidades, competências e habilidades explicitadas no PPC:

[...] o pedagogo deve ser preparado na perspectiva de ser capacitado para: [...] relacionar as linguagens dos meios de comunicação à educação, nos processos didático-pedagógicos, demonstrando domínio das tecnologias de informação e comunicação adequadas ao desenvolvimento de aprendizagens significativas [...] Quanto às suas competências e habilidades prevê-se, também: [...] Compreensão e valorização das diferentes linguagens e padrões culturais manifestados na sociedade contemporânea e de sua função na produção do conhecimento [...] (UEMG, 2008, p. 15-16).

No tocante à leitura das ementas na íntegra, percebemos algumas fragilidades de redação quando comparamos com as bibliografias básicas que as sustentam, supressão de informações relevantes para a compreensão do foco do componente curricular e/ou registros desnecessários para o seu entendimento de forma sintetizada. Sobre isso, Gatti e Nunes (2009, p. 31-31) esclarecem:

O entendimento a respeito da própria redação de uma ementa é diverso. A grande maioria dos proponentes entende que devem registrar uma lista de temas que formam o conjunto dos conteúdos trabalhados no período, um semestre ou um ano [...]. Outros entendem por ementa a explicitação de certas concepções em apenas um parágrafo, podendo ser entendida também como explicitação de um objetivo geral [...]. A diversidade de registros é expressiva, mostrando formas bem variadas, seja como um rol, uma lista, em muitos casos como resumo, sinopse ou descrição conceitual de procedimentos [...].

É possível que essa incoerência seja sanada quando da execução do programa dos componentes curriculares por meio da utilização de bibliografias complementares. Todavia, seria precipitado de nossa parte fazermos tal afirmação porque isso demandaria tanto um debruçar sobre os programas de cada componente curricular, os quais sofrem alterações semestralmente conforme as deliberações das respectivas áreas de conhecimento, quanto requereria observações participantes das aulas desses componentes, visto que, a compreensão das práticas de letramento demanda também "[...] conversar com as pessoas, ouvi-las e ligar as experiências imediatas de leitura e escrita (dos leitores) a outras coisas que elas também façam" (STREET, 2012, p. 78).

Por isso, dentro das limitações de uma análise documental, concordamos com o entendimento de Gatti e Nunes (2009, p. 32-33) e advertimos que: 
A adequação do texto das ementas à abordagem central em termos de conteúdos e objetivos a serem trabalhados em sala de aula torna-se relevante, pelo menos por três razões: revelar que o próprio professor conhece e sabe dizer de forma sintética o conjunto de temas a serem abordados para a formação dos futuros educadores; comunicar aos alunos os compromissos da disciplina, auxiliando no acompanhamento do currículo. $\mathrm{O}$ acesso dos alunos aos programas de ensino tem viabilizado movimentos discentes mais fundamentados e críticos em relação ao trabalho dos professores; ainda que menos diretamente relevante para o bom andamento do currículo, a redação adequada de ementas auxilia pesquisadores a se aproximarem de forma mais rigorosa do trabalho proposto em diferentes projetos pedagógicos.

Por tanto, a análise do currículo do curso presencial de licenciatura em Pedagogia da FaE/UEMG-CBH demonstrou que a formação cartográfica não possui visibilidade nesse curso. De uma forma aproximada, podemos supor que essa formação corresponda até e tão somente a $4 \%$ (quatro por cento) de horas aula, uma vez que tomando-se como referência o total de 4.432 (quatro mil, quatrocentos e trinta e duas) horas aulas que compõem o referido currículo, constatamos apenas 198 (cento e noventa e oito) horas aulas destinadas à área de conhecimento da Geografia, a qual ainda é partilhada com a área de História.

A única referência bibliográfica que assinala para uma formação cartográfica, apesar da sua suma importância para a compreensão das formas de representação do espaço geográfica, apresenta-se defasada, datando de quase duas décadas passadas.

Em relação às três categorias de análise que definimos para classificação das ementas que constituem o currículo em investigação, constatamos que a categoria de análise curricular 2 (Aprofundamento e diversificação de estudos específicos), a qual fixa-se nos conhecimentos relativos à formação e atuação profissional, em termos qualiquantitativos é a única em que se concentram as disciplinas da área de conhecimento da Geografia. Fazem parte dessa categoria as três e únicas disciplinas que tratam da formação geográfica do pedagogo: DMTE035 (NF4), DMTE057 (NF6) e DMTE081 (NF8).

Por toda a análise exposta, quando olhamos para o território que realmente ocupa a Cartografia no currículo do curso presencial de licenciatura em Pedagogia da FaE/UEMG-CBH, podemos afirmar que esse saber específico da Geografia não apenas apresenta-se desatualizado, segundo nos adverte Moreira (2007) sobre as fragilidades contemporâneas desse campo de estudo, como há uma desconsideração das contribuições teóricas dos novos estudos do letramento e uma invisibilidade da Cartografia nos componentes curriculares que se dedicam ao estudo da ciência geográfica. Para tanto, ilustramos no quadro abaixo como percebemos a formação geográfica no currículo do curso presencial de licenciatura em Pedagogia da FaE/ 
UEMG-CBH. Chamamos somente de formação geográfica porque não conseguimos caracterizar, com base nas ementas e bibliografias analisadas, como uma formação com enfoque cartográfico:

\section{Quadro 2 - O lugar da Cartografia no Curso de Pedagogia da FaE/UEMG-CBH}

\begin{tabular}{|c|c|c|c|}
\hline \multicolumn{4}{|c|}{$\begin{array}{l}\text { Categoria de análise curricular: } 1 \text {. Fundamentos teóricos da educação - estudos básicos } \\
\text { co: Visão crítico-reflexiva do fenômeno socioeducativo nas suas relações com a diversidade } \\
\text { e a multiculturalidade }\end{array}$} \\
\hline \multirow{2}{*}{$\frac{\text { DISCIPLINA }}{\text { EMENTA }}$} & \multicolumn{3}{|r|}{ CÓDIGO } \\
\hline & NF & $\mathrm{CH}$ & Bibliografia básica \\
\hline- & - & - & - \\
\hline \multicolumn{2}{|l|}{ Carga horária da categoria } & 00 & - \\
\hline \multicolumn{4}{|c|}{ Categoria de análise curricular: 2. Aprofundamento e diversificação de estudos específicos } \\
\hline \multicolumn{4}{|c|}{ Foco: Conhecimentos relativos à formação e atuação profissional específicos } \\
\hline $\begin{array}{c}\text { DISCIPLINA } \\
\text { Geografia e História: Conteúdos e Metodologias } \\
\text { na Educação Infantil e nos Anos Iniciais do } \\
\text { Ensino Fundamental }\end{array}$ & \multicolumn{3}{|r|}{$\begin{array}{l}\text { CÓDIGO } \\
\text { DMTE035 }\end{array}$} \\
\hline EMENTA & NF & $\mathrm{CH}$ & Bibliografia básica \\
\hline $\begin{array}{l}\text { Contextualização da prática pedagógica da } \\
\text { História e da Geografia na Educação Infantil e } \\
\text { nos anos iniciais do Ensino Fundamental: objetos } \\
\text { de estudo, concepções científicas e históricas. } \\
\text { Avaliação e construção da cidadania numa } \\
\text { perspectiva sóciohistórica. }\end{array}$ & 4 & 72 & $\begin{array}{l}\text { BUSQUETS, Maria Dolors et al. } \\
\text { Temas transversais em educação: } \\
\text { bases para uma formação integral. } \\
\text { Tradução Cláudia Chilling. 6. ed. São } \\
\text { Paulo: Ática, } 2003 \text {. } \\
\text { MORAES, A. C. R. Geografia: } \\
\text { pequena história crítica. 10. ed. São } \\
\text { Paulo: Hucitec, I995. } \\
\text { NEMI, Ana Lúcia Lana. Didática da } \\
\text { história: o tempo vivido: uma outra } \\
\text { história? São Paulo: FTD, } 1996 \text {. }\end{array}$ \\
\hline $\begin{array}{c}\text { DISCIPLINA } \\
\text { Geografia e História: Conteúdos e Metodologias } \\
\text { na Educação Infantil e nos Anos Iniciais do } \\
\text { Ensino Fundamental }\end{array}$ & \multicolumn{3}{|r|}{$\begin{array}{l}\text { CÓDIGO } \\
\text { DMTE057 }\end{array}$} \\
\hline EMENTA & NF & $\mathrm{CH}$ & Bibliografia básica \\
\hline $\begin{array}{l}\text { Contextualização da prática pedagógica em } \\
\text { História e Geografia nos primeiros anos do } \\
\text { Ensino Fundamental. Mediação de relação } \\
\text { homem/ mundo no tempo e no espaço. Propõe } \\
\text { vincular essa discussão com a construção, } \\
\text { implementação e avaliação de metodologias } \\
\text { apropriadas ao pensamento infantil, nesse nível } \\
\text { de escolaridade. }\end{array}$ & 6 & 72 & $\begin{array}{l}\text { CASTROGIOVANNI, Antônio Carlos } \\
\text { et al (org.). Geografia na sala de aula: } \\
\text { práticas e reflexões. Porto Alegre: } \\
\text { UFRGS, } 2001 . \\
\text { CITROM, Suzanne. Ensinar a } \\
\text { história hoje: a memória perdida } \\
\text { e reencontrada. Lisboa Livros } \\
\text { Horizonte, } 1990 \text {. } \\
\text { DOIN, Rosângela de Almeida; } \\
\text { YASUKO, Elza Passini. O espaço } \\
\text { geográfico: ensino e representação. } \\
9 \text { ed. São Paulo: Contexto, } 2001 .\end{array}$ \\
\hline
\end{tabular}




\begin{tabular}{|c|c|c|c|}
\hline $\begin{array}{c}\text { DISCIPLINA } \\
\text { Geografia e História: Conteúdos e Metodologias } \\
\text { na Educação Infantil e nos Anos Iniciais do } \\
\text { Ensino Fundamental }\end{array}$ & \multicolumn{3}{|r|}{$\begin{array}{c}\text { CÓDIGO } \\
\text { DMTE081 }\end{array}$} \\
\hline EMENTA & NF & $\mathrm{CH}$ & Bibliografia básica \\
\hline $\begin{array}{l}\text { O ensino de Geografia e História numa } \\
\text { perspectiva interdisciplinar e transdisciplinar. } \\
\text { Construção, implementação e avaliação de } \\
\text { projetos pedagógicos vinculados à visão } \\
\text { globalizadora do pensamento infantil. }\end{array}$ & 8 & 54 & $\begin{array}{l}\text { CASTROGIOVANNI, A. C et al. A } \\
\text { Geografia em sala de aula: práticas e } \\
\text { reflexões. 2. ed. Porto Alegre: Editora } \\
\text { da Universidade/UFRS/Associação } \\
\text { dos Geógrafos Brasileiros - Seção } \\
\text { Porto Alegre, 1999. } \\
\text { MORAES, A. C. R. Geografia: } \\
\text { pequena história crítica. 10. Ed. São } \\
\text { Paulo: Huciter, 1995. } \\
\text { NEMI, Ana Lúcia Martins. Didática } \\
\text { de história, o tempo vivido: uma outra } \\
\text { história? São Paulo: FTD, 1996. }\end{array}$ \\
\hline \multicolumn{2}{|l|}{ Carga horária da categoria } & 198 & - \\
\hline \multicolumn{4}{|c|}{ Categoria de análise curricular: 3 . Estudos integradores } \\
\hline \multicolumn{4}{|c|}{ Foco: Enriquecimento curricular } \\
\hline DISCIPLINA & \multicolumn{3}{|r|}{ CÓDIGO } \\
\hline EMENTA & NF & $\mathrm{CH}$ & Bibliografia básica \\
\hline- & - & - & - \\
\hline \multicolumn{2}{|c|}{ Carga horária da categoria } & 00 & - \\
\hline \multicolumn{2}{|c|}{ Carga horária total } & 198 & - \\
\hline \multicolumn{2}{|c|}{ Carga horária total do curso } & 4.432 & - \\
\hline
\end{tabular}

Fonte: Elaborado do autor a partir do PPC do currículo de Pedagogia da FaE/UEMG$\mathrm{CBH}, 2019$.

Esse quadro evidencia o panorama sobre a formação geográfica no currículo do curso presencial de licenciatura em Pedagogia da FaE/UEMG-CBH e resultou de uma análise minuciosa, mais direta, por meio da qual constatamos que apenas a disciplina DMTE057 (NF6) supostamente contempla o saber cartográfico, tendo em vista ser a única que apresenta bibliografia básica diretamente relacionada, ainda que desatualizada.

Preocupa-nos, também, o fato de que a Cartografia não se configura entre as temáticas sugeridas no currículo para os chamados estudos de "Enriquecimentos Curriculares", ofertados aos discentes a partir do segundo NF, como se destaca do PPC:

A partir do Núcleo Formativo II, o aluno tem a possibilidade de cursar estudos denominados "Enriquecimentos Curriculares". Esses estudos têm como objetivo aprofundar a formação do aluno, apresentando como eixo norteador a proposta de formação contemplada no Curso de Pedagogia. 
Cada Enriquecimento Curricular proposto deve conter carga horária de 40 horas/aula, que constará em seu Histórico Escolar.

A oferta de Enriquecimento Curricular poderá, ainda, incluir temáticas em consonância com as linhas de pesquisa da Instituição e com as demandas da comunidade acadêmica, após a devida aprovação pelo Colegiado de Curso.

Dentre outras, são exemplos de temas para proposição de Enriquecimentos Curriculares:

- Língua Portuguesa - Arte e Educação - Informática na Educação Educação nos Movimentos Sociais - Alfabetização de Adultos - Alunos com Necessidades Educacionais Especiais - Linguagens Especiais - Educação nas Empresas - Educação e Desenvolvimento Afetivo Sexual - Educação e Religião - Cultura e Educação - Educação e Juventude - Educação para Pessoas da Terceira Idade - Educação e Criatividade - Teatro, Cinema e Educação: perspectivas filosóficas, históricas e pedagógicas - Do mito ao Logos: A Revolução dos Filósofos Pré-Socráticos - na Cultura, Educação, Arte, Filosofia e Ciência do Ocidente e Oriente - Diversidade e Cidadania em Ambientes Escolares - Língua Brasileira de Sinais - LIBRAS (UEMG, 2008, p. 38).

Com a análise foi possível constatar que há uma invisibilidade do tipo de formação cartográfica que se oferece ao pedagogo da FaE/UEMG-CBH, da mesma forma em que a formação ampla em Geografia revela-se ínfima, uma vez que representa menos de $5 \%$ (cinco por cento) das horas totais do curso e é contemplada apenas nos NF 4, 5 e 8, sendo excluída dos demais momentos curriculares, ou seja, em mais da metade do curso.

\section{CONSIDERAÇÕES FINAIS}

Com este estudo, concluímos que há uma invisibilidade da formação cartográfica no currículo do curso presencial de licenciatura em Pedagogia da FaE/ UEMG-CBH. Ainda que disciplinas e/ou atividades acadêmicas outras explorem indiretamente essa temática, a formação curricular do pedagogo voltada para o aproveitamento das potencialidades que os estudos propiciados por teóricos que se dedicam à consolidação de uma concepção alargada de letramento especificamente no que concernem à formação de pedagogos cartograficamente letrados, não possui materialidade no curso analisado.

Alcançar essa visibilidade perpassa, todavia, por uma questão curricular, ou seja, demanda uma abertura dos currículos às indagações no campo do conhecimento, o que incide, segundo Arroyo (2011, p. 50), em disputas entre seus sujeitos em torno do controle nos territórios do currículo: "Territórios sagrados a serem cultuados. Logo, controlados com novos rituais. O próprio campo do conhecimento objeto de disputa político-libertadora passa a ser objeto de controle".

Diante desse campo de disputas, demarcar o território da Cartografia no currículo do curso presencial de licenciatura em Pedagogia da FaE/UEMG-CBH 
significa lidar com questões outras que envolvem a história dos cursos de Pedagogia no Brasil, por isso, não sejamos ingênuos, demarcar esse território não se trata apenas de uma questão pedagógica mas envolve, sobretudo, o campo interno da alfabetização e do letramento, onde há muitas tensões, dentre as quais: radicalismos teóricos, disputas de currículos, metodologias e o uso de dados para culpabilizar professores e sistemas de ensino. Tensões essas que, dada a profundidade do tema, serão problematizadas em um outo estudo.

\section{REFERÊNCIAS}

ALMEIDA, R. D. de; PASSINI, E. Y. O espaço geográfico: ensino e representação. 7. ed. São Paulo: Contexto, 1999.

ARROYO, M. G. Currículo, território em disputa. Petrópolis, RJ: Vozes, 2011. Associados, 1985.

BARTON, D. Literacy: an introduction to the ecology of written language. 2nd ed. Oxford: Blackwell, 2007.KRESS, Gunther. Literacy in the new media age. London: Routledge, 2007.

BERTIN, J. Teste de base da representação gráfica. Tradução Antônio Teixeira Neto. Revista Brasileira de Geografia, Rio de Janeiro, 42 (1): jan-mar, 1980, p. 160-182

BICALHO, D. C. Leitura. In: FRADE, I. C. A. S; VAL, M. da G. C. G; BREGUNCI, M. das G. C. Glossário Ceale de termos de Alfabetização, leitura e escrita par educadores. Belo Horizonte, CEALE/Faculdade de Educação da UFMG. 2014. Disponível em: htttp://www.ceale.fae.ufmg.br/app/webroot/glossarioceale/ verbetes/ leitura. Acesso em: 18 abr. 2019.

BOGDAN, R.; B. S. K. Investigação Qualitativa em Educação - uma introdução à teoria e aos métodos. Porto: Porto Editora, 1994.

CARVALHO, F. F. Os significados composicionais e a formação de subjetividades na primeira página de jornais mineiros: um estudo de caso à luz da gramática do design visual. 2007. 124 p. Dissertação (Pós-graduação em Estudos Linguísticos). Faculdade de Letras, Universidade Federal de Minas Gerais, Belo Horizonte, 2007.

CHARTIER, R. A aventura do livro: do leitor ao navegador. Trad. Reginaldo de Moraes. São Paulo: Editora UNESP/ Imprensa Oficial do Estado, 1999. 
ALVES, DC; FRADE, ICAS. Letramento cartográfico do pedagogo: uma análise curricular de um curso superior de pedagogia. Revista @mbienteeducação. São Paulo: Universidade Cidade de São Paulo, v. 13, n. 2, p. 253-277 Mai/Ago 2020.

COSCARELLI, C. V. Textos versus hipertextos na teoria e na prática. In: COSCARELLI, C. V. (Org.) Hipertextos na teoria e na prática. Belo Horizonte: Autêntica, 2012.

CRAMPTON, J. W.; KRYGIER, J. An introduction to critical cartography. ACME: An international e-journal for critical geographies, v. 4, n.1, 2006, p.11-33.

DIONÍSIO, A. P.; VASCONCELOS, L. J. de. Multimodalidade, gênero textual e leitura. In: BUNZEN, C.; MENDONÇA, M. (Orgs.) Múltiplas linguagens para o ensino médio. São Paulo: Parábola Editorial, 2013.

FERREIRO, E. Reflexões sobre Alfabetização. São Paulo: Cortez/Autores, 1985.

FISCHER, S. R. História da Leitura. Trad. Claudia Freire. São Paulo: Editora Unesp, 2006.

FRADE, I. C. A. S. Alfabetização digital. In: VAL, M. da G. C. G; BREGUNCI, M. das G. C. Glossário Ceale de termos de Alfabetização, leitura e escrita par educadores. Belo Horizonte, CEALE/Faculdade de Educação da UFMG. 2014. Disponível em: http://ceale.fae.ufmg.br/app/webroot/glossarioceale/referencia/ frade-i-c-a-s-alfabetizacao-digital-problematizacao-do-conceito-e-possiveisrelacoes-com-a-pedagogia-e-com-aprendizagem-inicial-do-sistema-de-escrita-incoscarelli-c-e-ribeiro-e-orgs-letramento-digital-aspectos-sociais-e-possibilidadespedagogicas-belo-horizonte-autentica-2005. Acesso em: 18 abr. 2019.

FREIRE, P. A importância do ato de ler: em três artigos que se completam. São Paulo, Autores Associados: Cortez, 1989.

GATTI, B. A. Formação de professores para o ensino fundamental: estudo de currículos das licenciaturas em pedagogia, língua portuguesa, matemática e ciências biológicas / Bernardete A. Gatti; Marina Muniz R. NUNES (orgs.) são Paulo: FCC/ DPE, 2009.

GIL, A. C. Como elaborar projetos de pesquisa. $4^{\mathrm{a} e d .}$ São Paulo: Editora Atlas, 2002.

GOVERNO DO ESTADO DE MINAS GERAIS. Lei n. 11.539, de 22 de julho de 1994. Dispõe sobre a Universidade do Estado de Minas Gerais - UEMG - e dá outras providências. Disponível em: https://www.almg.gov.br/consulte/legislacao/ completa/ completa-nova- min.html? tipo=LEl\&num=11539\&comp=\&ano=1994\&texto=original. Acesso em: 05 jun. 2019.

JENKINS, H. Cultura da Convergência. 2.ed. - São Paulo: Aleph, 2009. 
KENSKI, V. M. Educação e tecnologias: o novo ritmo da informação. 8. ed. Campinas, SP: Papirus, 2012.

KRESS, G; BEZEMER, J. Escribir en un mundo de representación multimodal. In: KALMAN e STREET (Coord.) Lectura, escritura e matemáticas: Diálogos com a América Latina. México: single XXI, 2009.

MANEVY, A. Política da Cultura Digital. In: SAVAZONI, R.; CONH, S. (Org.). Cultura digital.br. Rio de Janeiro: Beco do Azougue, 2009.

MOREIRA, R. Pensar e Ser em geografia. São Paulo: Contexto, 2007.

PARAÍSO, M. A. Diferença no Currículo. Cadernos de Pesquisa, v.40, n.140, p. 587604, maio/ago. 2010.

PINTO, A. V. O conceito de Tecnologia. Rio de Janeiro: Contraponto, 2005.

RAFFESTIN, C. Repères pour une théorie de la territorialité humaine. Cahier/ Groupe Réseaux, (7), 1987.

RAFFESTIN, C. Por uma geografia do poder. São Paulo: Ática, 1993.

SANTAELLA, L. Navegar no ciberespaço: o perfil cognitivo do leitor imersivo. São Paulo: Paulus, 2004.

SIMIELLI, M. E. R. Cartografia no ensino fundamental e médio. In: CARLOS, Ana Fani Alessandri (org.) A Geografia na sala de aula. São Paulo: Contexto, 2002.

STREET, B. Eventos de letramento e práticas de letramento: teoria e prática nos Novos Estudos do Letramento. In: MAGALHÂES, I. (Org.) Discursos e práticas de letramento: Pesquisa etnográfica e formação de professores. Campinas: Mercado de Letras, 2012.

UNIVERSIDADE DO ESTADO DE MINAS GERAIS - UEMG. Plano de Desenvolvimento Institucional. Disponível em: http://intranet.uemg.br/comunicacao/ arquivos/PDI_final_site.pdf. Acesso em: 10 jul. 2018.

UNIVERSIDADE DO ESTADO DE MINAS GERAIS. Graduação. Projeto Pedagógico do Curso presencial de Pedagogia da FaE/UEMG, 2008. Disponível em: http:// www.uemg.br/graduacao/cursos2/course/pedagogia. Acesso em: 14 dez. 2019. 


\section{SOBRE OS AUTORES}

DANIEL CARDOSO ALVES. Doutorando em Educação pela FaE/UFMG; Mestre em Ciências Ambientais, Especialista em Análise do Espaço Geográfico e Licenciado em Geografia pela UESB/BA; Professor adjunto da FaE/UEMG.

ISABEL CRISTINA ALVES DA SILVA FRADE. Doutorado em Educação pela Universidade Federal de Minas Gerais (2000) e pós doutorado pela FE/USP /Brasil e Institut National de Recherche Pédagogique/França (2006/2007) e pela UDESC/ SC (2011/2012).Professora titular da FAE/UFMG, atuando na Pós-Graduação, graduação em Pedagogia pela Pontifícia Universidade Católica de Minas Gerais (1980), Mestrado em Educação pela Universidade Federal de Minas Gerais (1993). Instituição: Universidade Federal de Minas Gerais.

RECEBIDO: 08/04/2020.

APROVADO: 29/04/2020. 